\title{
Effectiveness of Pleurotus eryngii (King Oyster Mushroom) Extract for Killing Larvae and Attracting Adult Mosquito Vectors in Samut Songkhram Province of Thailand
}

Tanawat Chaiphongpachara*, Aegkapun Bumrungsuk, Chichanok Chitsawaeng, Kantima Sumchung and Kitthisak Khlaeo Chansukh

College of Allied Health Sciences, Suan Sunandha Rajabhat University, Thailand

*Corresponding author: Tanawat Chaiphongpachara, College of Allied Health Sciences, Suan Sunandha Rajabhat University, Thailand, Tel: +66835865775; E-mail: tanawat.ch@ssru.ac.th

Received date: June 27, 2018; Accepted date: July 10, 2018; Published date: July 17, 2018

Copyright: (c) 2018 Chaiphongpachara T, et al. This is an open-access article distributed under the terms of the Creative Commons Attribution License, which permits unrestricted use, distribution and reproduction in any medium, provided the original author and source are credited.

\begin{abstract}
In this study, we assessed the efficiency of Pleurotus eryngii mushroom extract for killing larvae and attracting adult mosquito vectors (Aedes aegypti and Culex sitiens) in the Samut Songkhram province of Thailand. Five extract concentrations $(120,12,1.2,0.12$ and $0.012 \mathrm{mg} / \mathrm{L})$ were used for larvicidal tests, while 3 concentrations (100, 10, and $1 \mathrm{mg} / \mathrm{L}$ ) were examined for adult mosquito attraction. The larvicidal results showed that $P$. eryngii extract did not kill $A$ e. aegypti larvae, while the extract had minimal effect on $C x$. sitiens larvae except at $1.2 \mathrm{mg} / \mathrm{L}$. $P$. eryngii extract most attracted adult $A e$. aegypti and $C x$. sitiens mosquitoes at $10 \mathrm{mg} / \mathrm{L}$, followed by 1 and $100 \mathrm{mg} / \mathrm{L}$, respectively. Further, statistical analysis revealed a significantly different number of mosquitoes that responded to $P$. eryngii extract and octenol. This research demonstrated that this mushroom extract could be developed to attract mosquitoes, although only one concentration $(10 \mathrm{mg} / \mathrm{L})$ attracted more than half of all Ae. aegypti adults.
\end{abstract}

Keywords: Killing larvae; Attracting mosquito; Pleurotus eryngii; Mosquito vector

\section{Introduction}

Mosquitoes carry many human diseases that are major public health issues around the world, especially in tropical and sub-tropical countries [1]. Mosquito-borne diseases include dengue fever, chikungunya, malaria, filariasis, West Nile virus, yellow fever, Zika virus, and Japanese encephalitis, and according to World Health Organization (WHO) estimates, more than one million people die from these diseases every year [2,3]. Thailand has epidemic areas of mosquito-borne diseases, primarily because it is located in a tropical area. In 2017, the Thai Ministry of Public Health reported a total of 65,000 patients suffered from mosquito-borne diseases [4]. This number indicates that these disease are a major problem and should be resolved urgently.

There are two ways to control mosquito vectors, namely reducing the number of larvae or adult mosquitoes. Temephos, a chemical that is not toxic to humans or animals, is widely used on mosquito larvae in all parts of Thailand [5]. However, long-term use of these chemical causes vector resistance. Indeed, temephos resistance has been reported in many areas of Thailand, and this phenomenon makes it difficult to control the mosquito population [6]. Further, temephos use is usually successful only for Aedes spp., especially Ae. aegypti, since its spawning habits are in household water containers [7]. Other mosquito species, such as Culex spp. and Anopheles spp., spawn in large water resources in nature. It is unlikely that temephos can or will be used for larvae control.

Octenol (1-octen-3-ol) is a volatile substance that emanates from human sweat and breath. Female mosquitoes use this scent to find bait to suck blood to obtain the blood protein that is required for egg development [8]. Currently, many types of mosquito traps use octenol to increase the efficiency of mosquito attraction. One such trap, the mosquito magnet [9], exhibits high performance, but its expense makes it unpopular in Thailand. It has been reported that octenol can found in mushrooms and it is reportedly toxic to insect larvae [10]. Therefore, it is possible that edible mushrooms in Thailand could be developed for use as larvicides and as substances that attract mosquitoes to replace the expensive synthetic substances on the market.

In this study, we examined the popular and edible king oyster mushroom (Pleurotus eryngii), reported to contain octenol as a component [11], to study its efficacy and efficiency for killing larvae and attracting adult mosquito vectors in the laboratory. This study was conducted using prominent mosquito vectors in coastal areas of Samut Songkhram province, including Ae. aegypti, a dengue fever vector, and $C X$. sitiens, a filariasis and Japanese encephalitis vector [12]. We hypothesised that this extract could reduce mosquito numbers in this area and consequently further reduce the number of new patients with mosquito-borne diseases.

\section{Materials and Methods}

\section{Mushroom collection}

P. eryngii was collected from the Talat Thai market, Khlong Luang district, Pathum Thani province, the center of trade in agricultural

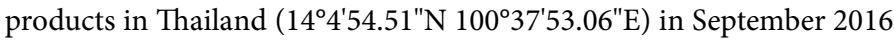
(Figure 1). Mushroom samples were transported to the College of Allied Health Sciences (Suan Sunandha University, Samut Songkhram province). Specimens were identified morphologically using the mushroom taxonomic keys [13-16]. 
Citation: Chaiphongpachara T, Bumrungsuk A, Chitsawaeng C, Sumchung K, Chansukh KK (2018) Effectiveness of Pleurotus eryngii (King Oyster Mushroom) Extract for Killing Larvae and Attracting Adult Mosquito Vectors in Samut Songkhram Province of Thailand. Biol Med (Aligarh) 10: 444. doi:10.4172/0974-8369.1000444

Page 2 of 4

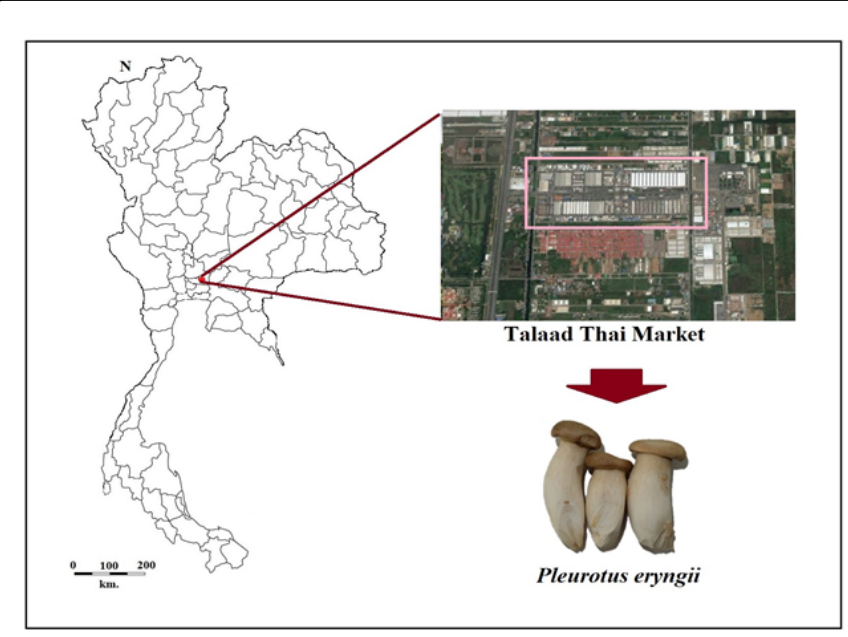

Figure 1: Location of the collection site.

\section{Mushroom extraction}

P. eryngii samples were cut into small pieces and fermented with $95 \%$ ethanol at room temperature for $48 \mathrm{~h}$. The mushroom extract was filtered and evaporated under reduced pressure at $50^{\circ} \mathrm{C}$ using a rotary evaporator to obtain the crude extract. The crude extract was then dried by freeze dehydration at $-85^{\circ} \mathrm{C}$ for approximately $24 \mathrm{~h}$. The yields of $P$. eryngii extract were weighed, recorded, dissolved in ethanol and stored at $-20^{\circ} \mathrm{C}$ before laboratory testing.

\section{Mosquito rearing}

Ae. aegypti (Bola Bola strain, F171) were obtained from the Faculty of Tropical Medicine (Mahidol University). CX. sitiens were collected from the coastal area of Samut Songkhram province, which is $200 \mathrm{~m}$ away from the sea $\left(13^{\circ} 23^{\prime} 31.57^{\prime \prime} \mathrm{N} 100^{\circ} 1^{\prime} 59.36 " \mathrm{E}\right)$, using a standard mosquito dipper in a water source with a salinity level of more than 0.05 parts per thousand (ppt). Ae. aegypti eggs and $C x$. sitiens larvae were placed in separate trays $(25 \times 30 \times 5 \mathrm{~cm})$ that contained filtered water; $0.1 \mathrm{~g}$ dog food was provided daily. When eggs or larvae reached the pupae stage, they were transferred to cages $(30 \times 30 \times 30 \mathrm{~cm})$ to facilitate adult emergence.

\section{Bioassay for $P$. eryngii extract larvicidal effect}

Larvicidal tests were modified according to WHO [17]. Five concentrations of extract were used $(120,12,1.2,0.12$ and $0.012 \mathrm{mg} / \mathrm{L})$. Filtered water containing the appropriate concentration of the substance was added to 6 ounce glasses and 20 late third instar or early forth instar larvae were added. After $24 \mathrm{~h}$, the number of dead larvae was recorded. For the control group, only solvent was added to the filtered water in the test glass. Each concentration was repeated 3 times.

\section{Bioassay to test $\boldsymbol{P}$. eryngii extract adult mosquito attraction}

Three concentrations of mushroom extract were used to test adult mosquito attraction $(100,10$, and $1 \mathrm{mg} / \mathrm{L})$. We conducted this bioassay using a modified $\mathrm{Y}$ tube, according to Geier et al. [18], using 20 mosquitoes per concentration. Mosquitoes were released into the tube, which has 2 sides: the left contained $P$. eryngii extract and the right contained solvent. The number of mosquitoes that flew to each end was counted and recorded. This experiment was repeated 3 times for each concentration.

\section{Data analysis}

The number of dead larvae or attracted mosquitoes are expressed as the mean \pm standard deviation (S.D.). Statistical comparison for adult attraction between $P$. eryngii extract and octenol was performed using a two-tailed t-test. $\mathrm{p}<0.05$ was considered statistically significant.

\section{Results}

P. eryngii extract had no effect on Ae. aegypti larvae, while the extract minimally killed $C x$. sitiens larvae at all concentrations except $1.2 \mathrm{mg} / \mathrm{L}$ (Table 1). The highest octenol concentration $(120 \mathrm{mg} / \mathrm{L})$ killed less Ae. aegypti than $C X$. sitiens larvae $(9.33 \pm 4.93$ compared to $19.67 \pm 0.58$, respectively). For the $P$. eryngii control group, no larval death was observed, while the octenol control group caused slight larval death for Ae. aegypti $(0.33 \pm 0.58$; Table 1$)$ and $C X$. sitiens $(1.33$ \pm 0.58 ; Table 1 ).

\begin{tabular}{|l|l|l|l|l|l|}
\hline \multirow{2}{*}{ Concentration (mg/L) } & \multirow{2}{*}{$\mathbf{n}$} & \multicolumn{4}{|c|}{ Mean \pm S.D. number of dead larvae } \\
\cline { 3 - 6 } & & & \multicolumn{2}{|c|}{ P. eryngii } & \multicolumn{2}{c|}{ Octenol } \\
\cline { 3 - 6 } & & Ae. aegypti & Cx. sitiens & Ae. Aegypti & Cx. sitiens \\
\hline 120 & 20 & $0.00 \pm 0.00$ & $1.33 \pm 1.53$ & $9.33 \pm 4.93$ & $19.67 \pm 0.58$ \\
\hline 12 & 20 & $0.00 \pm 0.00$ & $1.67 \pm 0.58$ & $0.33 \pm 0.58$ & $9.67 \pm 3.06$ \\
\hline 1.2 & 20 & $0.00 \pm 0.00$ & $0.00 \pm 0.00$ & $0.00 \pm 0.00$ & $0.00 \pm 0.00$ \\
\hline 0.12 & 20 & $0.00 \pm 0.00$ & $0.67 \pm 0.58$ & $1.00 \pm 1.00$ & $5.00 \pm 2.65$ \\
\hline 0.012 & 20 & $0.00 \pm 0.00$ & $0.67 \pm 0.58$ & $0.33 \pm 0.58$ & $5.00 \pm 2.65$ \\
\hline
\end{tabular}

Table 1: Mean number of dead Ae. aegypti and CX. sitiens larvae.

The $10 \mathrm{~g} / \mathrm{mL}$ concentration of $P$. eryngii extract attracted the most adult Ae aegypti and CX. sitiens mosquitoes, followed by 1 and 100 $\mathrm{g} / \mathrm{mL}$ concentrations, respectively. The $10 \mathrm{~g} / \mathrm{mL}$ octenol concentration also attracted the most adults for both species (Figure 2). At all concentrations, $P$. eryngii extract attracted more Ae. aegypti than $C X$. sitiens adults (Figure 2). However, compared to all octenol 
Citation: Chaiphongpachara T, Bumrungsuk A, Chitsawaeng C, Sumchung K, Chansukh KK (2018) Effectiveness of Pleurotus eryngii (King Oyster Mushroom) Extract for Killing Larvae and Attracting Adult Mosquito Vectors in Samut Songkhram Province of Thailand. Biol Med (Aligarh) 10: 444. doi:10.4172/0974-8369.1000444

Page 3 of 4

concentrations, $P$. eryngii extract attracted significantly fewer adult mosquitoes for both species (Figure 2).

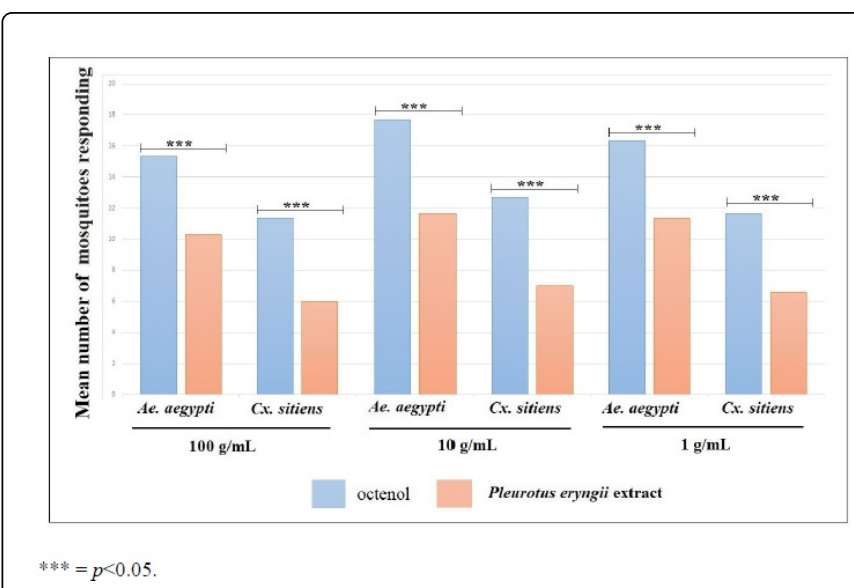

Figure 2: Statistical comparison between the mean numbers of mosquitoes attracted by $P$. eryngii extract or octenol.

\section{Discussion}

In this study, we investigated the effectiveness of $P$. eryngii mushroom extract for killing larvae and attracting adult mosquitoes. We found that $P$. eryngii extract was ineffective in killing Ae. aegypti larvae, but it appeared mildly larvicidal toward $C x$. sitiens at certain concentrations. However, the minimal $C X$. sitiens larval death may be due to our use of larvae from nature (rather than a laboratory strain), since the number of larval deaths in the extract and control groups were similar. Thus, $P$. eryngii extract is not suitable to kill mosquito larvae in the field. This finding is consistent with previous research from Thongwat et al. [19] who screened the ability of 143 mushroom species in Thailand to kill mosquito larvae and found them to be almost entirely ineffective. There were only 6 mushroom species with potential larvicidal activity, all of which were wild, expensive and seasonal. Thus, it appears quite difficult to further develop a product to control mosquito larvae based on mushroom extracts.

For adult mosquito control, mosquito traps are an effective control option with substantial interest worldwide. Currently, mosquito trap development focuses on optimising traps to avoid polluting the environment [20]. The use of odor in traps is one of the most important tools used to increase the effectiveness of mosquito control. Octenol is a powerful mosquito attractant [21], but it is expensive. It attracts mosquitoes because it emanates from humans and animals that would serve as prey for blood-feeding female mosquitoes [22]. Several studies have documented that mushrooms, including $P$. eryngii, contain octenol [11]. The results in this study showed that 10 $\mathrm{g} / \mathrm{mL}$ P eryngii extract most effectively attracted adult mosquitoes. This finding is consistent with other octenol research that demonstrated higher octenol concentrations did not necessarily attract mosquitoes more efficaciously than lower concentrations [8]. Since the insect odor system has a specific odor range, it varies according to mosquito species.

Our research found that $P$. eryngii extract attracted Ae. aegypti better than $C_{X}$. sitiens at all concentrations. This finding is similar to previous research by Cilek et al. [23] that reported that octanol attracted Ae. albopictus better than $C X$. quinquefasciatus. However, at all concentrations $P$. eryngii extract attracted significantly fewer adult mosquitoes than octenol. Nevertheless, at $10 \mathrm{~g} / \mathrm{mL}$, the extract attracted more than half of all Ae. aegypti mosquitoes (58.33\%).

\section{Conclusion}

These finding is the first to demonstrate that $P$. eryngii extract could possibly be developed to further enhance mosquito lure efficiency. Although the performance of $P$. eryngii extract is different with octanol but extract was effective in attracting more than half of all mosquitoes in the laboratory. The advantages of this extract are an inexpensive and eco-friendly way to increase the efficiency of mosquito traps.

\section{Acknowledgements}

We would like to thank the College of Allied Health Science, Suan Sunandha Rajabhat University, Thailand, for their kind support of our research.

\section{References}

1. Service M (2008) Medical entomology for students (4th edn.). Cambridge University Press, pp. 306.

2. World Health Organization (2014) WHO Factsheets: Vector-borne diseases. Factsheet number 387 [Internet] 10.

3. World Health Organization, (2016) WHO Fact Sheet: World Malaria Report [Internet]. Fact Sheet World Malar Rep.

4. Ministry of Public Health, Thailand (2017) Annual report. Accessed 15 Dec 2017.

5. Chaiphongpachara T, Moolrat L (2017) Insecticide resistance of temephos on Aedes aegypti as dengue vector in Samut Songkhram, Thailand. Ann Trop Med Public Health 10: 1439-1442.

6. Jirakanjanakit N, Saengtharatip S, Rongnoparut P, Duchon S, Bellec C, et al. (2007) Trend of Temephos Resistance in Aedes (Stegomyia) Mosquitoes in Thailand During 2003-2005. Environ Entomol 36: 506-511.

7. Chaiphongpachara T, Pimsuka S, Saisanan Na Ayudhaya W, Wassanasompong W (2017) The application of geographic information system in dengue haemorrhagic fever risk assessment in Samut Songkhram province, Thailand. Int J Geomate 12: 53-60.

8. Grant AJ, Dickens JC (2011) Functional characterization of the octenol receptor neuron on the maxillary palps of the yellow fever mosquito, Aedes aegypti. PLoS One 6: e21785..

9. Hoel DF, Kline DL, Allan SA, Grant A (2007) Evaluation of carbon dioxide, 1-octen-3-ol, and lactic acid as baits in mosquito magnet pro traps for Aedes albopictus in north central florida. J Am Mosq Control Assoc 23: 11-17.

10. Yin G, Padhi S, Lee S, Hung R, Zhao G, et al. (2015) Effects of Three Volatile Oxylipins on Colony Development in Two Species of Fungi and on 1-octen-3-ol Larval Metamorphosis. Curr Microbiol 71: 347-356.

11. Mau JL, Lin YP, Chen PT, Wu YH, Peng JT (1998) Flavor Compounds in King Oyster Mushrooms Pleurotus eryngii. J Agric Food Chem 46: 4587-4591.

12. Chaiphongpachara $\mathrm{T}$, Sumruayphol $\mathrm{S}$ (2017) Species diversity and distribution of mosquito vectors in coastal habitats of Samut Songkhram province, Thailand. Trop Biomed 34: 524-532.

13. Largent DL (1986) How to identify mushrooms to genus I: macroscopic features. Eureka Printing, Eureka.

14. Largent DL, Baroni TJ (1988) How to identify mushrooms to genus VI: modern genera. Eureka Printing, Eureka.

15. Largent DL, Johnson D, Watling R (1977) How to identify mushrooms to genus III: microscopic features. Eureka Printing, Eureka.

16. Largent DL, Thiers HD (1977) How to identify mushrooms to genus II: field identification of genera. Eureka Printing, Eureka. 
Citation: Chaiphongpachara T, Bumrungsuk A, Chitsawaeng C, Sumchung K, Chansukh KK (2018) Effectiveness of Pleurotus eryngii (King Oyster Mushroom) Extract for Killing Larvae and Attracting Adult Mosquito Vectors in Samut Songkhram Province of Thailand. Biol Med (Aligarh) 10: 444. doi:10.4172/0974-8369.1000444

Page 4 of 4

17. World Health Organization (2016) Monitoring and managing insecticide resistance in Aedes mosquito populations Interim guidance for entomologists. World Heal Organ.

18. Geier M, Boeckh J (1999) A new Y-tube olfactometer for mosquitoes to measure the attractiveness of host odours. Entomol Exp Appl 92: 9-19.

19. Thongwat D, Pimolsri U, Somboon P (2015) Screening for mosquito larvicidal activity of Thai mushroom extracts with special reference to steccherinum sp against Aedes aegypti (L.) (Diptera: Culicidae). Southeast Asian J Trop Med Public Health 46: 586-595.

20. Kweka EJ, Owino EA, Lee MC, Dixit A, Himeidan YE, et al. (2013) Efficacy of resting boxes baited with Carbon dioxide versus CDC light trap for sampling mosquito vectors: A comparative study. Glob Heal Perspect 11-8.
21. Magalhães-Junior JT, Barrouin-Melo SM, Corrêa AG, DA Rocha Silva FB, Machado VE, et al. (2014) A laboratory evaluation of alcohols as attractants for the sandfly Lutzomyia longipalpis (Diptera: Psychodidae). Parasites \& Vectors 7: 60

22. Bohbot JD, Durand NF, Vinyard BT, Dickens JC (2013) Functional development of the octenol response in Aedes aegypti. Front Physiol 4: 39.

23. Cilek JE, Ikediobi CO, Hallmon CF, Johnson R, Onyeozili EN, et al. (2011) Semi-field evaluation of several novel alkenol analogs of 1 octen-3-ol as attractants to adult Aedes albopictus and Culex quinquefasciatus. J Am Mosq Control Assoc 27: 256-262. 